OPEN ACCESS

Edited by:

Samir G. Sakka,

Witten/Herdecke University, Germany

Reviewed by:

Michael A. Dubick,

United States Army Institute of

Surgical Research, United States

Marina Soro,

Hospital Clinico Universitario de

Valencia, Spain

*Correspondence:

Pierre Squara pierre.squara@orange.fr

Specialty section:

This article was submitted to Intensive Care Medicine and Anesthesiology,

a section of the journal

Frontiers in Medicine

Received: 22 September 2017 Accepted: 02 November 2017

Published: 20 November 2017

Citation:

Nguyen LS and Squara P (2017) Non-Invasive Monitoring of Cardiac

Output in Critical Care Medicine.

Front. Med. 4:200.

doi: 10.3389/fmed.2017.00200

\section{Non-Invasive Monitoring of Cardiac Output in Critical Care Medicine}

\author{
Lee S. Nguyen and Pierre Squara* \\ Critical Care Medicine Department, CMC Ambroise Paré, Neuilly-sur-Seine, France
}

Critically ill patients require close hemodynamic monitoring to titrate treatment on a regular basis. It allows administering fluid with parsimony and adjusting inotropes and vasoactive drugs when necessary. Although invasive monitoring is considered as the reference method, non-invasive monitoring presents the obvious advantage of being associated with fewer complications, at the expanse of accuracy, precision, and stepresponse change. A great many methods and devices are now used over the world, and this article focuses on several of them, providing with a brief review of related underlying physical principles and validation articles analysis. Reviewed methods include electrical bioimpedance and bioreactance, respiratory-derived cardiac output (CO) monitoring technique, pulse wave transit time, ultrasound $\mathrm{CO}$ monitoring, multimodal algorithmic estimation, and inductance thoracocardiography. Quality criteria with which devices were reviewed included: accuracy (closeness of agreement between a measurement value and a true value of the measured), precision (closeness of agreement between replicate measurements on the same or similar objects under specified conditions), and step response change (delay between physiological change and its indication). Our conclusion is that the offer of non-invasive monitoring has improved in the past few years, even though further developments are needed to provide clinicians with sufficiently accurate devices for routine use, as alternative to invasive monitoring devices.

Keywords: non-invasive monitoring, cardiac output, hemodynamics, critical care medicine, bioreactance

\section{INTRODUCTION}

Hemodynamic instability requires cardiac output $(\mathrm{CO})$ measurement and tracking to assess severity of disorders and to adjust treatments on a continuous basis. Invasive monitoring is widely used but is associated with inherent iatrogenic complications, notably for pulmonary catheters, esophageal probes, or arterial catheters (1-3). Therefore, non-invasive methods offer a safer approach even though their metrologic performance remains challenged, particularly in intensive care units (ICUs) $(4,5)$.

This article aims to review such non-invasive methods of $\mathrm{CO}$ monitoring excluding echographic, thermodilution, and pulse contour methods, already described in other sections. We will cover electrical bioimpedance and bioreactance, respiratory-derived $\mathrm{CO}$ monitoring technique, ultrasound $\mathrm{CO}$ monitoring, multimodal algorithmic estimation, and inductance thoracocardiography.

Devices are reviewed using three main metrologic criteria required for $\mathrm{CO}$ measurement: trueness (systematic error assessed by the closeness of agreement between the average of an infinite number of replicate measurements and the true or reference value), precision (random error assessed by the closeness of agreement between replicate measurements on the same or similar objects under 
TABLE 1 | Summarizes the metrologic performance of these different technologies.

\begin{tabular}{|c|c|c|c|c|c|c|c|}
\hline Device & Author & Year & $\begin{array}{c}\text { Number of } \\
\text { patients }\end{array}$ & ICU setting & Mean bias (1/min) & Percentage error $(\%)$ & $\begin{array}{c}\text { Precision } \\
\text { (repeatability) }\end{array}$ \\
\hline Bioimpedance & Peyton and Chong (69) & 2010 & 435 (pooled) & Yes & $-0.1 \pm 1.1$ & Mild & nd \\
\hline Bioreactance & Squara (20) & 2007 & 110 & Yes & $+0.16 \pm 0.52$ & Mild & $12 \%$ \\
\hline \multirow[t]{3}{*}{$\mathrm{CO}_{2}$ rebreathing } & Kotake et al. (38) & 2009 & 42 & Yes & $+0.18 \pm 0.88$ & Mild & nd \\
\hline & Peyton and Chong (69) & 2010 & 167 (pooled) & Mixed & $-0.05 \pm 2.24$ & Mild & nd \\
\hline & Opotowsky et al. (45) & 2017 & 12232 & Mixed & $-0.4 \pm 2.24$ & High & nd \\
\hline Ultrasonic & Chong and Peyton (71) & 2012 & 320 (pooled) & Yes & $-0.39 \pm 0.14$ & Poor & nd \\
\hline Pulse wave velocity & Yamada et al. (51) & 2012 & 213 & Yes & $+0.13 \pm 1.15$ & Acceptable & nd \\
\hline Inductance cardiography & Kaplan et al. (66) & 2003 & 11 & No & $+0.2 \pm 2.4$ & Mild & nd \\
\hline
\end{tabular}

specified conditions), and step response change (delay between physiological change and its indication) (6). Table 1 summarizes the metrologic performance of all reviewed technologies.

\section{BIOIMPEDANCE AND BIOREACTANCE}

Bioimpedance was first described in aeronautical medicine 50 years ago (7). It shares physical principles with bioreactance. It involves delivery of a low-amplitude high-frequency electrical current $(I)$ across the thorax and received voltage $(V)$ by electrodes. Hemodynamic variables: stroke volume (SV), CO, and thoracic fluid content (TFC) are then derived from the output signal fluctuation. Thoracic impedance $(Z)$ is defined by the ratio $V / I$. At baseline $\left(Z_{\mathrm{o}}\right)$ is the ratio of maximum values of $V$ and $I\left(V_{\mathrm{o}} / I_{\mathrm{o}}\right)$ and closely correlated changes in TFC (8-17). In the presence of flow through the aorta $Z_{0} Z$ decreases over time proportionally to the increase of water and iron located in the chest, thus, to the increase in blood volume. Traditional bioimpedance systems use amplitude modulation as signal whereas bioreactance systems use frequency modulation and phase shifts (see Figure 1) (18). The theoretical superiority of the frequency modulation is its easier electric noise filtration (19).

A basic hypothesis to derive $\mathrm{CO}$ from both impedance and reactance is that the heart chambers are electrically isolated. Indeed, relatively to the chest with the lungs, the myocardial wall effectively provides electrical isolation to the content of the heart; therefore, changes in chest impedance and reactance are closely linked to variations of aortic volume. SV is obtained from the product of the ventricle ejection time and the slope of the initial change of the aortic volume obtained from the first derivative of the impedance or reactance signal $\left(\mathrm{d} Z / \mathrm{d} t_{\max }\right.$ or $\left.\mathrm{d} X / \mathrm{d} t_{\max }\right)$. Since these changes only indicate relative changes of $\mathrm{CO}$, a calibration factor (CF) is necessary, based on an initial cohort of patients to derive absolute values

$$
\begin{gathered}
\mathrm{SV}=\mathrm{VET} \times \mathrm{d} Z / \mathrm{d} t_{\max } \times \mathrm{CF} \\
\mathrm{SV}=\mathrm{VET} \times \mathrm{d} X / \mathrm{d} t_{\max } \times \mathrm{CF} .
\end{gathered}
$$

Several physical and anatomical hypotheses are required, limiting the effectiveness of impedance/reactance, most notably when there is no association between aortic systolic deformation and the SV (i.e., aortic dissection, aortic prosthesis), when hematocrit is very low, when pulmonary arterial pressure is elevated (for which, correction factors exist) or because of physical abnormalities such as obesity and dehydration (20).
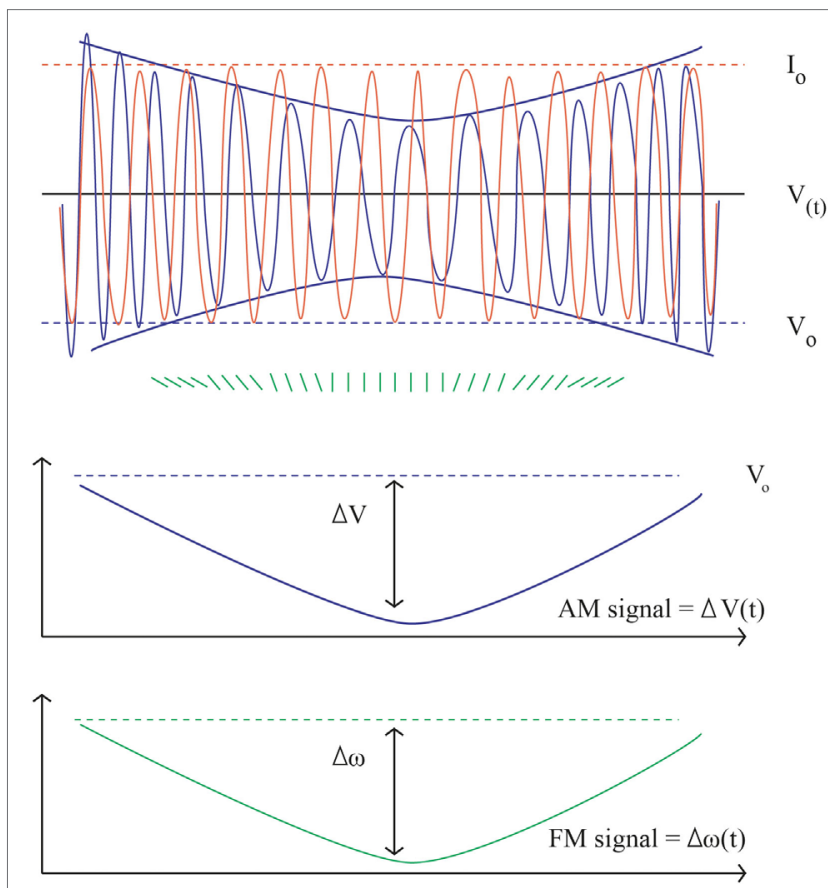

FIGURE 1 | Bioimpedance and bioreactance signal. Upper part, in orange the input constant alternating current: $I_{\circ}=5 \mathrm{~mA}$, frequency $75 \mathrm{kHz}$ ( $\omega=150,000$ radians/s). In blue the output voltage. $V(t)=200 \pm 2 \mathrm{mV}$, frequency $F(t)=75 \mathrm{kHz} \pm 5 \mathrm{~Hz}$. The instantaneous changes in phase are figured in green. In the middle, the $V_{0}$ envelope (AM component) is extracted from the envelope of $V=4 \mathrm{mV}$, corresponding to the bioimpedance signal $(Z=4 / 5=0.8 \Omega)$. The lower part shows the corresponding changes in frequency as obtained by the sum of instant phase shift (FM signal) figuring the bioreactance signal: $F=10 \mathrm{~Hz}(\omega=20$ radians/s). Using appropriate scaling the shape of the AM and FM signals is the same.

Devices using bioimpedance include NCCOM (Bomed Medical, Irvine, CA, USA), BioZ (Cardiodynamics, San Diego, CA, USA), NICCOMO (MEDIS, Limenau, Germany), ICON (Osypka Cardiotronic, Berlin, Germany), ICG (Philips Medical Systems, Andover, MA, USA), NICOMON (Larsen and Toubro Ltd., Mumbai, India), the CSM3000 (Cheers Sails Medical, Shenzhen, China), and PHYSIOFLOW (Manatec Biomedical, Paris, France). The NICaS system (NI Medical, Petah-Tikva, Israel) uses the same principles but applied to the whole body. In the ECOM system (Ecom Medical, San Juan Capistrano, CA, USA), the transmitting and receiving electrodes are located on 
the cuff of an endotracheal tube, therefore close to the ascending aorta, in order to minimize the impact of analogous signals from other cardiac structures. Bioreactance is used by two products from the same company NICOM and Starling (Cheetah medical, Wilmington, DE, USA).

Bioimpedance and bioreactance have the strong advantage of being totally non-invasive and low costs. Literature on bioimpedance includes hundreds of articles, dozens of which are clinical trials set in a wide range of situations from ambulatory patients at home, to patients in a physiology laboratories, during surgery and in a ICU. Results are somewhat contradictory (21). At least a third of the publications failed to assess bioimpedance as a reliable mean to assess $\mathrm{CO}$ (22-25). Focusing on positive articles, most of them took place outside from an ICU setting most often in situations where the absolute value of CO has less importance than relative changes (26-30). This may be explained as electronical environment is heavier in ICU (due to the number of monitoring devices) compared to traditional medicine department; the higher the level of noise, the lesser bioimpedance would be accurate because of an unfavorable signal/noise ratio. Moreover, total body impedance is less accurate than localized thoracic impedance. Finally, even though last iterations of this technology seem more advanced (such as electrical velocimetry), results are not quite as clear either $(31,32)$. As of today, bioimpedance is not consensually viewed as accurate enough to estimate CO in ICU.

Bioreactance on the other hand has scarcer documentation. Theoretical superiority of bioreactance over bioimpedance was hinted in small sample studies set, in quite homogeneous patients of cardiac surgery ICU where the CF was derived $(33,34)$. In two studies, the accuracy, delay and amplitude of the signal were found similar to that of continuous thermodilution, although a bias up to $20 \%$ was found in $20 \%$ of patients. In other words, bioreactance-measured CO was similar to that of thermodilution in $80 \%$ of patients, but in those in whom it was not, bias could be as high as $20 \%$. In several other studies investigating more heterogeneous patients, results were not considered as acceptable $(35,36)$. Concerns may be raised about decrease in accuracy during low-flow state and when electrocauterization was performed.

Further developments may be required to improve bioimpedance and bioreactance performance focusing or better understanding of the signal composition and better extraction of the aortic expansion signal. The auto calibration process may also be improved to fit better the studied population.

\section{RESPIRATORY DERIVED CO MONITORING SYSTEM: PARTIAL $\mathrm{CO}_{2-}$ REBREATHING}

Applying Fick principles to exhaled gases allows measuring CO, by assessing oxygen consumption $\left(\mathrm{VO}_{2}\right)$ and the difference of arterial $\left(\mathrm{CaO}_{2}\right)$ and venous $\left(\mathrm{CvO}_{2}\right)$ blood oxygen contents. This method was first described for intubated, sedated and ventilated patients (who did not present severe gas-exchange abnormality), using either oxygen $\left(\mathrm{O}_{2}\right)$ or carbon dioxide $\left(\mathrm{CO}_{2}\right)$ exhaled gas, and requires invasive arterial and mixed venous blood sampling, obeying the following equations (37):

$$
\begin{gathered}
\mathrm{CO}=\mathrm{VO}_{2} / \mathrm{CaO}_{2}-\mathrm{CvO}_{2} \\
\mathrm{CO}=\mathrm{VCO}_{2} / \mathrm{CaCO}_{2}-\mathrm{CvCO}_{2} .
\end{gathered}
$$

A non-invasive method has since been developed, using the slope of $\mathrm{CO}_{2}$ dissociation curve $(\mathrm{S})$ and the end tidal $\mathrm{CO}_{2}$ concentration $\left(\mathrm{S}\right.$. etCO $\mathrm{CO}_{2}$ ) as a surrogate of $\mathrm{CaCO}_{2}$. Since the $\mathrm{CvCO}_{2}$ is more difficult to estimate, it is derived considering two periods of time: normal respiration $(n)$ and a 30 -s period of rebreathing $(r)$. Assuming that the $\mathrm{CO}$ and the $\mathrm{CvCO}_{2}$ remain unchanged during the two periods of time, the two equations become as follow:

$$
\begin{aligned}
& \mathrm{VO}_{2} / \mathrm{CaO}_{2}-\mathrm{CvO}_{2}=n \mathrm{VCO}_{2} / n\left(\mathrm{~S} \text {. etCO } \mathrm{Cl}_{2}\right)-\mathrm{CvCO}_{2} \\
& \mathrm{VCO}_{2} / \mathrm{CaCO}_{2}-\mathrm{CvCO}_{2}=r \mathrm{VCO}_{2} / r(\mathrm{~S} \text {. etCO } 2)-\mathrm{CvCO}_{2} \\
& \text { Hence: } \mathrm{CO}=n \mathrm{VCO}_{2} / n\left(\mathrm{~S} \text {. etCO}{ }_{2}\right)-\mathrm{CvCO}_{2} \\
& =r \mathrm{VCO}_{2} / r\left(\mathrm{~S} \text {. etCO }{ }_{2}\right)-\mathrm{CvCO}_{2} \\
& \text { Finally: } \mathrm{CO}=\Delta \mathrm{VCO}_{2} / \Delta\left(\mathrm{S} \text {. etCO }{ }_{2}\right) \text {. }
\end{aligned}
$$

etCO $\mathrm{C}_{2}$ can be measured in exhaled gas with a sealed facial mask. This partial $\mathrm{CO}_{2}$-rebreathing method hence allows measuring $\mathrm{CO}$ without the need of intravascular monitoring devices. Practical use involves an extra loop of ventilatory circuit to create a transient partial $\mathrm{CO}_{2}$ rebreathing system (i.e., etCO ${ }_{2}$ ) (see Figure 2).

The NICO-sensor (Philips Respironics, Eindhoven, the Netherlands) and INNOCOR (Innovision ApS, Denmark) are based on these principles $(38,39)$. Several limitations surround this method: (a) the smallest variations in $\mathrm{CO}_{2}$ can lead to significant differences in $\mathrm{CO}$ measurements, i.e., the slightest leaks in facial mask can induce measurement bias, (b) changes in ventilation modify end-tidal $\mathrm{CO}_{2}$ requiring patient respiratory state to be steady, i.e., not applicable in ICU, and (c) differences in $\mathrm{VCO}_{2}$ and end-tidal $\mathrm{CO}_{2}$ only account for that part of the lung which is ventilated, hence, atelectasis or intrapulmonary shunts need to be adjusted for, which in an ICU setting can prove difficult when patients present with several lung diseases (40-42). The two most recent validation articles published were small-sample studies in which this method was compared with thermodilution. Both failed to prove the equivalence between the two methods $(43,44)$.

A very recent retrospective study, in more than 12,000 patients who underwent right heart catheterization but were not necessarily hospitalized in ICU, found between thermodilution and an oxygen-uptake-based Fick method, an acceptable systematic bias of $0.4 \%$ but poor limits of agreement from -1.31 to $+1.27 \mathrm{l} / \mathrm{min}$; and a difference of more than $20 \%$ between measured CO in $40 \%$ of patients (45).

Hence, partial $\mathrm{CO}_{2}$-rebreathing is still hard to routinely use in ICU but fields of development include better rebreather-face interface to avoid leaks (i.e., masks) and correction algorithms which may take into account changes in end-tidal $\mathrm{CO}_{2}$, all the more in ICU setting. Indeed, this latter concern seems particularly difficult to address, as acute respiratory disease (including acute pulmonary edema, pneumonia and chronic obstructive 


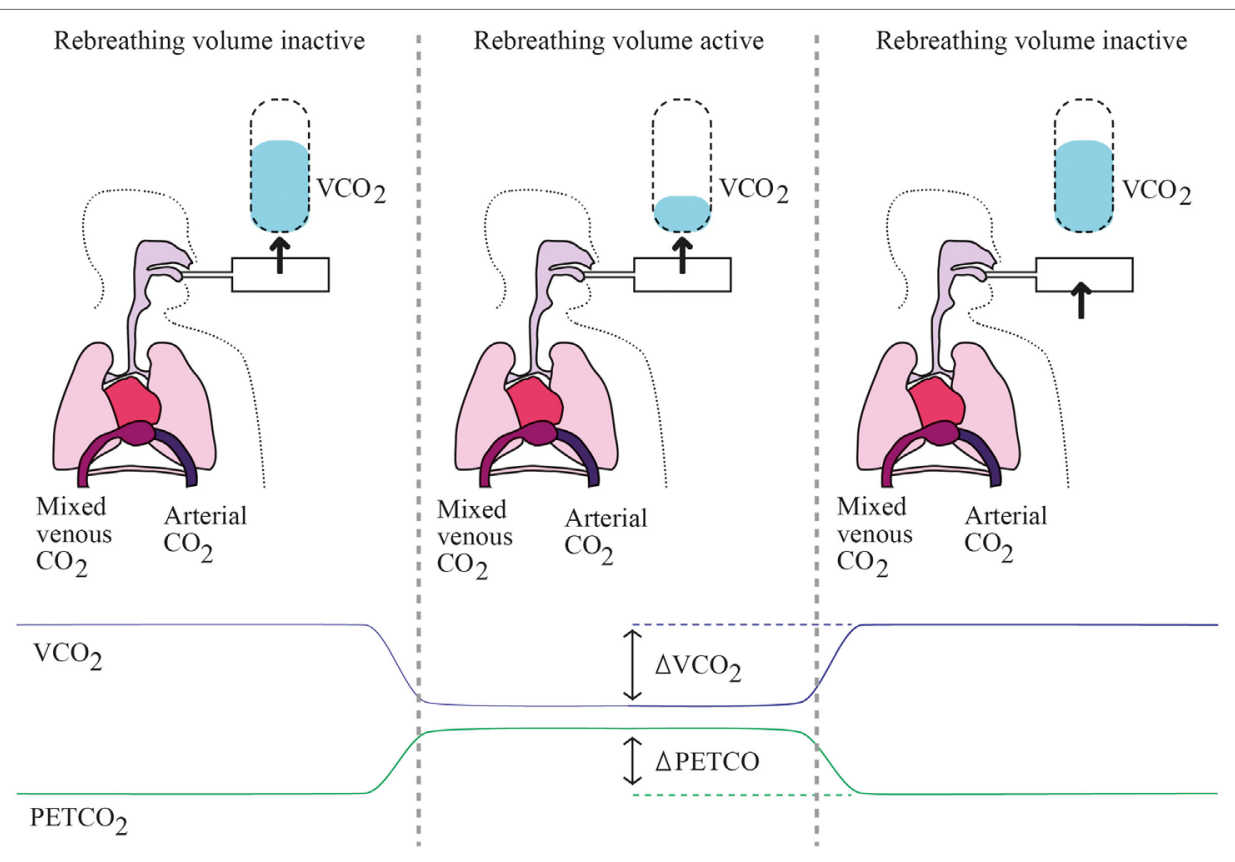

FIGURE 2 | Partial rebreathing principles. Left panel represents baseline state, where the rebreathing valve is off and every parameter is at baseline levels. Middle panel represents early rebreathing time, when the valve is put; there is a decrease of $\mathrm{VCO}_{2}$ with simultaneous rise in $\mathrm{PaCO}$ and $\mathrm{PETCO}_{2}$. Right panel represents late rebreathing time when valve is off again and all parameters return to baseline levels, while mixed venous PCO2 has varied.

pulmonary disease exacerbation) represents the most prevalent cause of admission in ICU.

\section{PULSE WAVE TRANSIT TIME (PWTT)}

Pulse wave transit time is the time required for a pulse pressure wave to travel between two points. It can be estimated from the time interval between the development of the R-wave on the electrocardiogram and its peripheral detection (see Figure 3). Approximating systemic blood circulation to a three-component Windkessel circuit (integrating aortic characteristic impedance, arterial compliance, and systemic vascular resistance) and neglecting vascular inertance, blood pressure can be associated with blood flow hence $\mathrm{CO}$ in a complex non-linear function (46, 47). PWTT is then considered inversely correlated with the SV (48). With increasing blood pressure, increasing arterial distending pressure and decreasing arterial compliance, pulse-wave velocity increases and PWTT shortens. Hence, PWTT was suggested as a surrogate measure of blood pressure changes. Given a known and fixed distance between the heart and the extremity on which the measurement is made, PWTT can be computed using the following Bramwill and Hill formula (49):

$$
P W V=\mathrm{d} P . V / \rho . \mathrm{d} V
$$

where PWV = pulse wave velocity; $\rho=$ density of blood; $V=$ initial vessel volume; $\mathrm{d} P=$ the change in pressure; and $\mathrm{d} V=$ the change in vessel volume.

One product uses this technology (EsCCO, Nihon Kohden, Japan). Continuous CO is estimated with a multimodal algorithm

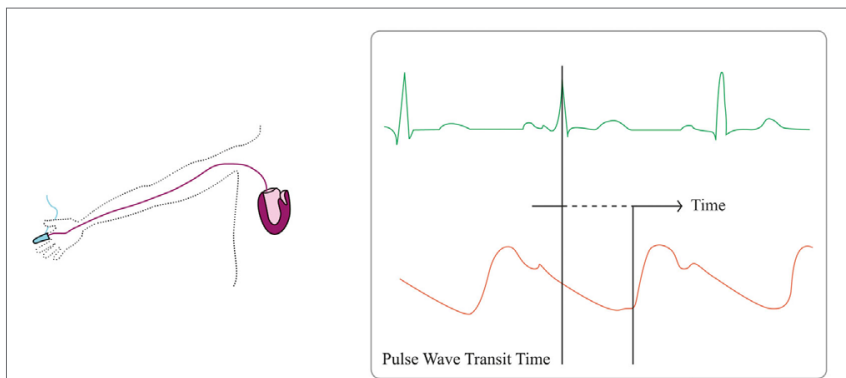

FIGURE 3 | Pulse wave transit time principles. Pulse wave transit time is based on the delay of the generation of a stroke volume (orange line) after the generation of the R-wave on the electrocardiogram (green line).

PWV and using patients' characteristics and several measurements such as pulse oximeter waveform, non-invasively measured blood pressure and electrocardiogram. The final formula is given by:

$$
\mathrm{SV}=K \times(\alpha \times \mathrm{PWTT}+\beta)
$$

where the unique variable is PWTT then inversely proportional to velocity. Other determinants are $\alpha=-0.3$, experimental proportional constant according to unpublished preliminary data and $K$ and $\beta$ are individual CFs based on physical profile (age, weight, height) and the initial measurement of the pulse pressure. Interestingly, initial CO was estimated only by this non-invasive patient information calibration (50). Even if later refined by an automated exclusion algorithm, several concerns were raised as 
to its accuracy in ICU setting (51-55). Indeed, although systematic bias was acceptable with $0.13 \mathrm{l} / \mathrm{min}$, limits of agreement were poor (between -2.13 and $2.39 \mathrm{l} / \mathrm{min}$ ) (51). Limitations include vasoconstriction, cold extremities and arrhythmias all of which induce bias in measurements. Moreover, while calibration with invasive means seems to enhance the trueness of this device; there is uncertainty as to its stability (51). Finally, catecholamines infusions are a limitation to the use of plethysmographic-variabilitybased indices in critically ill patients $(56,57)$.

While EsCCO has not been quite validated in ICU, devices using pulse wave contour analysis, working quite closely to pulse wave velocity analysis are more promising. EsCCO suffers mainly from initial individual calibration issues, which are reduced to a crude algorithm aggregating a few variables which may not be sufficient to account for the wide variability of patients presenting in ICU. Indeed, the two main issues are (i) the heterogeneity of patients' profiles, for which an overall algorithm may be statistically true for most but containing an inherent percentage error, making individual prediction hard to assess and (ii) the interpatient variability in the course of his treatment and care in ICU (accounting for volemia, vasoconstriction or vasodilation, catecholamine use and arrhythmia, to name a few).

\section{ULTRASONIC METHODS}

Product of aortic blood flow velocity and area of a section of the aorta equals to the $\mathrm{CO}$ measured in the aorta. Blood flow velocity can be measured using ultrasound and Doppler effect

$$
\mathrm{SV}=\mathrm{VTI} \text {. CSA, }
$$

where VTI = aortic flow velocity time integral and CSA $=$ aortic cross-sectional area. Hence, a non-invasive measurement method would require a device continuously measuring aortic blood flow, in a fixed manner (see Figure 4). This method is used in the ultrasonic cardiac output-monitoring (USCOM) device. USCOM requires the precalculation of the aortic valve area based on patient's age and weight. Moreover, ICU setting seems to be inadequate for using USCOM (58-60). Limitations include (i) the difficulty of keeping the USCOM Doppler probe in a steady position on a critically ill patient, (ii) the lack of echogenicity in patients who underwent cardiac surgery (61), and (iii) the reliability of the valve area estimation based on age and weight tends to decrease with population age $(62,63)$.

A few articles highlight the feasibility of using USCOM in ICU, with a systematic bias of $-0.361 / \mathrm{min}$ however limits of agreement were poor ranging from -2.34 to $1.62 \mathrm{l} / \mathrm{min}$ and the reported percentage error (29\%) seemed too high for daily use (64).

To put it in a nutshell, although point-of-care ultrasonic evaluation of CO is widely used in ICU, continuous echocardiographic monitoring of CO by USCOM remains largely debated. Indeed, a high percentage error, either due to errors in valve area estimation or probe displacement, make it hard to routinely apply. However, initial calibration on actual echocardiographic assessment of the valve area and regular signal-quality checks may improve this technique.

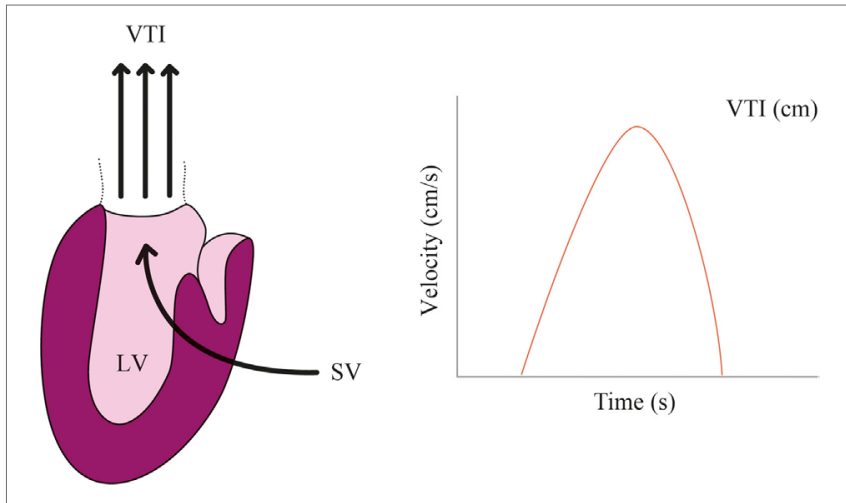

FIGURE 4 | Echocardiographic monitoring. Aortic flow velocity time integra (VTI) multiplied by the cross-sectional area (CSA) allows to compute stroke volume (SV) ejected by the left ventricle $(\mathrm{LV})$. Heart rate $(\mathrm{HR})$ then allows to compute cardiac output $(\mathrm{CO})=\mathrm{VTI} \times \mathrm{CSA} \times \mathrm{HR}$.

\section{INDUCTANCE THORACOCARDIOGRAPHY}

This method allows the computation of ventricular volume curves from ECG-triggered ensemble respiratory waveform of an inductive plethysmographic transducer. The latter is placed on the thorax by surrounding with a belt. Impedance varies according to respiration and cardiac ejection. Because the transducer is positioned in front of the heart, heartbeat-related ventricular volume variations are detected and adjusting the signal on respiratory-related impedance signal allows computing specific cardiac changes. The only device using this technology is Respitrace (Noninvasive Monitoring Systems, Miami, FL, USA) (65).

Main limitation of this method resides in the fact that it only detects relative variations in cardiac volumes $(66,67)$, hence, at least one calibration per patient is required to get an absolute value (68). Moreover, if thoracic compliance is very low, cardiac volume variations can be undetectable. Finally, although the method was published at the end of the 90s, only a few publications have since been written by a few authors only, making external validation difficult to assess. In 2017, inductance thoracocardiography seem like it fell out of clinical practice, maybe to the exception of a few experimental settings.

\section{DISCUSSION}

The need for a non-invasive, true and precise $\mathrm{CO}$ measurement in the ICU is, as of yet, still unsatisfied $(69,70)$, despite acceptable results on other settings. As recent reviews demonstrated, overall, validation articles available in the field of non-invasive hemodynamic monitoring showed too large heterogeneity and devices, insufficient levels of agreement. Thus, further research may be warranted in the field, as hemodynamic monitoring is bound to be less and less invasive in the future.

Extensive reviewing of published data on diagnostic performance of monitoring devices, be they invasive or not, shows heterogeneity in reporting of performance. Specifically, accuracy, i.e., how close a single measurement value is to the true value of 
the measurand can never be numerically assessed. Indeed, the true value of the measurand can only be approximated by a reference method or, when available, a gold-standard. Theoretically, if someone could repeat the measurement an infinite number of times to estimate the same measurand value, the only difference between the averaged observed value and the true value would equal the systematic measurement error (i.e., systematic bias qualifying the trueness). Statistical analyses are aimed for adjusting for such bias, however, most methods derive from populationbased algorithms, hence do not account for individual variability. Therefore, non-invasive devices are characterized by acceptable mean interpatient bias but poor individual calibration. Precision, as defined by metrological standards, represents the repeatability and reproducibility of the method, i.e., the degree to which repeated measurements using the same method to estimate the same measurand value, produce the same observed value. Inherently, it relates to random measurement error (as opposed as systematic measurement error represented by the bias). As such, most publications do not specify precision but rather publish the standard deviation of the bias in the cohort, i.e., interpatient bias. A higher precision allows for fewer measurements in order to have an estimation of the measurand. Hence, precision has a direct practical impact on the usability of devices, especially in the step time response of the device. Indeed, very few articles describe how many measurements were taken to obtain a value, and similarly, manufacturers do not always specify how many measurements are necessary to be within acceptable error limits. In practice, non-invasive devices present the obvious advantage of allowing repeated measures to obtain more accurate value, given they would be adequately calibrated. However, if a given

\section{REFERENCES}

1. Cruz K, Franklin C. The pulmonary artery catheter: uses and controversies. Crit Care Clin (2001) 17:271-91. doi:10.1016/S0749-0704(05)70167-6

2. Huttemann E, Schelenz C, Kara F, Chatzinikolaou K, Reinhart K. The use and safety of transoesophageal echocardiography in the general ICU - a minireview. Acta Anaesthesiol Scand (2004) 48:827-36. doi:10.1111/j.0001-5172. 2004.00423.x

3. Frezza EE, Mezghebe H. Indications and complications of arterial catheter use in surgical or medical intensive care units: analysis of 4932 patients. Am Surg (1998) 64:127-31.

4. Marik PE, Baram M. Noninvasive hemodynamic monitoring in the intensive care unit. Crit Care Clin (2007) 23:383-400. doi:10.1016/j.ccc. 2007.05.002

5. Squara P, Imhoff M, Cecconi M. Metrology in medicine: from measurements to decision, with specific reference to anesthesia and intensive care. Anesth Analg (2015) 120:66-75. doi:10.1213/ANE.0000000000000477

6. Squara P, Cecconi M, Rhodes A, Singer M, Chiche JD. Tracking changes in cardiac output: methodological considerations for the validation of monitoring devices. Intensive Care Med (2009) 35:1801-8. doi:10.1007/s00134009-1570-9

7. Kubicek WG, Karnegis JN, Patterson RP, Witsoe DA, Mattson RH. Development and evaluation of an impedance cardiac output system. Aerosp Med (1966) 37:1208-12.

8. Nierman DM, Eisen DI, Fein ED, Hannon E, Mechanick JI, Benjamin E. Transthoracic bioimpedance can measure extravascular lung water in acute lung injury. J Surg Res (1996) 65:101-8. doi:10.1006/jsre.1996.0350

9. Newman RB, Pierre H, Scardo J. Thoracic-fluid conductivity in peripartum women with pulmonary edema. Obstet Gynecol (1999) 94:48-51. doi:10.1097/00006250-199907000-00009 device takes too long to estimate a measurand, its usefulness may be challenged, however accurate it can be.

Hence, the risk of misdiagnosis or delay to diagnosis from an insufficiently accurate non-invasive device remains real. Indeed, they represent the counterparts of invasive device-related complications, be they infections or hemorrhages. Consequently, properly assessing the need for invasive monitoring remains a clinical challenge in ICU, to which, the only acceptable solution would be equally efficient non-invasive devices.

Interestingly, obtaining the true value of a measurand would not necessarily be the most important feature that one might require from a hemodynamic monitoring device. Indeed, ability to observe variations in hemodynamics is equally important, if not more; implying fast step-time response and precision. Observing the decrease in CO may be as useful as knowing this exact value. In the end, the difference between trueness and precision may be analogous to that of diagnosis or monitoring.

\section{CONCLUSION}

Non-invasive monitoring has evolved in the past few years, seeing the appearance of promising new devices. Further developments may be warranted to validate their use and increase their metrologic performance in ICU. Even though some have successfully deployed such device, the need for a non-invasive, true and precise $\mathrm{CO}$ measurement in ICU is, as of yet, still unsatisfied.

\section{AUTHOR CONTRIBUTIONS}

\section{LN and PS contributed equally to the manuscript.}

10. Saunders CE. The use of transthoracic electrical bioimpedance in assessing thoracic fluid status in emergency department patients. Am J Emerg Med (1988) 6:337-40. doi:10.1016/0735-6757(88)90151-9

11. Metry G, Mallmin H, Wikstrom B, Danielson BG. Proportional changes in body fluid with hemodialysis evaluated by dual-energy X-ray absorptiometry and transthoracic bioimpedance with particular emphasis on the thoracic region. Artif Organs (1997) 21:969-76. doi:10.1111/j.1525-1594.1997.tb00510.x

12. Zerahn B, Jensen BV, Olsen F, Petersen JR, Kanstrup IL. The effect of thoracentesis on lung function and transthoracic electrical bioimpedance. Respir Med (1999) 93:196-201. doi:10.1016/S0954-6111(99)90008-2

13. Peacock WI, Albert NM, Kies P, White RD, Emerman CL. Bioimpedance monitoring: better than chest $\mathrm{x}$-ray for predicting abnormal pulmonary fluid? Congest Heart Fail (2000) 6:86-9. doi:10.1111/j.1527-5299.2000.80141.x

14. Moharram EE, El Attar AM, Kamel MA. The impact of anesthesia on hemodynamic and volume changes in operative hysteroscopy: a bioimpedance randomized study. JClin Anesth (2017) 38:59-67. doi:10.1016/j. jclinane.2016.06.023

15. Malfatto G, Blengino S, Perego GB, Branzi G, Villani A, Facchini M, et al. Transthoracic impedance accurately estimates pulmonary wedge pressure in patients with decompensated chronic heart failure. Congest Heart Fail (2012) 18:25-31. doi:10.1111/j.1751-7133.2011.00248.x

16. Cagini L, Capozzi R, Tassi V, Savignani C, Quintaliani G, Reboldi G, et al. Fluid and electrolyte balance after major thoracic surgery by bioimpedance and endocrine evaluation. Eur J Cardiothorac Surg (2011) 40:e71-6. doi:10.1016/j. ejcts.2011.03.030

17. Malfatto G, Branzi G, Giglio A, Villani A, Facchini C, Ciambellotti F, et al. Transthoracic bioimpedance and brain natriuretic peptide levels accurately indicate additional diastolic dysfunction in patients with chronic advanced systolic heart failure. Eur J Heart Fail (2010) 12:928-35. doi:10.1093/eurjhf/ hfq089 
18. Imhoff M, Lehner JH, Lohlein D. Noninvasive whole-body electrical bioimpedance cardiac output and invasive thermodilution cardiac output in high-risk surgical patients. Crit Care Med (2000) 28:2812-8. doi:10.1097/ 00003246-200008000-00022

19. Keren H, Burkhoff D, Squara P. Evaluation of a noninvasive continuous cardiac output monitoring system based on thoracic bioreactance. Am J Physiol Heart Circ Physiol (2007) 293:H583-9. doi:10.1152/ajpheart.00195.2007

20. Squara P. Bioreactance: a new method for non-invasive cardiac output monitoring. Yearbook of Intensive Care and Emergency Medicine. (2008). p. 619-30.

21. Raaijmakers E, Faes TJ, Scholten RJ, Goovaerts HG, Heethaar RM. A meta-analysis of three decades of validating thoracic impedance cardiography. Crit Care Med (1999) 27:1203-13. doi:10.1097/00003246199906000-00053

22. Barry BN, Mallick A, Bodenham AR, Vucevic M. Lack of agreement between bioimpedance and continuous thermodilution measurement of cardiac output in intensive care unit patients. Critical Care (1997) 1:71-4. doi:10.1186/cc92

23. Hirschl MM, Kittler H, Woisetschlager C, Siostrzonek P, Staudinger T, Kofler J, et al. Simultaneous comparison of thoracic bioimpedance and arterial pulse waveform-derived cardiac output with thermodilution measurement. Crit Care Med (2000) 28:1798-802. doi:10.1097/00003246-200006000-00017

24. Marik PE, Pendelton JE, Smith R. A comparison of hemodynamic parameters derived from transthoracic electrical bioimpedance with those parameters obtained by thermodilution and ventricular angiography. Crit Care Med (1997) 25:1545-50. doi:10.1097/00003246-199709000-00023

25. Preiser JC, Daper A, Parquier JN, Contempre B, Vincent JL. Transthoracic electrical bioimpedance versus thermodilution technique for cardiac output measurement during mechanical ventilation. Intensive Care Med (1989) 15:221-3. doi:10.1007/BF00271054

26. Barin E, Haryadi D, Schookin S, Westenskow D, Zubenko V, Beliaev K, et al. Evaluation of a thoracic bioimpedance cardiac output monitor during cardiac catheterization. Crit Care Med (2000) 28:698-702 . doi:10.1097/00003246200003000-00016

27. Kac G, Durain E, Amrein C, Herisson E, Fiemeyer A, Buu-Hoi A. Colonization and infection of pulmonary artery catheter in cardiac surgery patients: epidemiology and multivariate analysis of risk factors. Crit Care Med (2001) 29:971-5. doi:10.1097/00003246-200105000-00014

28. Spiess B, Patel M, Soltow L, Wright I. Comparison of bioimpedance versus thermodilution cardiac output during cardiac surgery: evaluation of a second-generation bioimpedance device. J Cardiothorac Vasc Anesth (2001) 15:567-73. doi:10.1053/jcan.2001.26533

29. Albert NM, Hail MD, Li J, Young JB. Equivalence of the bioimpedance and thermodilution methods in measuring cardiac output in hospitalized patients with advanced, decompensated chronic heart failure. Am J Crit Care (2004) 13:469-79.

30. Sageman WS, Riffenburgh RH, Spiess BD. Equivalence of bioimpedance and thermodilution in measuring cardiac index after cardiac surgery. J Cardiothorac Vasc Anesth (2002) 16:8-14. doi:10.1053/jcan.2002.29635

31. Heringlake M, Handke U, Hanke T, Eberhardt F, Schumacher J, Gehring H, et al. Lack of agreement between thermodilution and electrical velocimetry cardiac output measurements. Intensive Care Med (2007) 33:2168-72. doi:10.1007/s00134-007-0828-3

32. Zoremba N, Bickenbach J, Krauss B, Rossaint R, Kuhlen R, Schalte G. Comparison of electrical velocimetry and thermodilution techniques for the measurement of cardiac output. Acta Anaesthesiol Scand (2007) 51:1314-9. doi:10.1111/j.1399-6576.2007.01445.x

33. Marqué S, Cariou A, Chiche JD, Squara P. Comparison between FlotracVigileo and Bioreactance, a totally noninvasive method for cardiac output monitoring. Crit Care (2009) 13(3):R73. doi:10.1186/cc7884

34. Cheung H, Dong Q, Dong R, Yu B. Correlation of cardiac output measured by non-invasive continuous cardiac output monitoring (NICOM) and thermodilution in patients undergoing off-pump coronary artery bypass surgery. J Anesth (2015) 29:416-20. doi:10.1007/s00540-014-1938-z

35. Fagnoul D, Vincent JL, de Backer D. Cardiac output measurements using the bioreactance technique in critically ill patients. Critical Care (2012) 16:460. doi:10.1186/cc11481

36. Kim JY, Kim BR, Lee KH, Kim KW, Kim JH, Lee SI, et al. Comparison of cardiac output derived from FloTrac/Vigileo and impedance cardiography during major abdominal surgery. J Int Med Res (2013) 41:1342-9. doi:10.1177/0300060513487649
37. Lee AJ, Cohn JH, Ranasinghe JS. Cardiac output assessed by invasive and minimally invasive techniques. Anesthesiol Res Pract (2011) 2011:475151. doi:10.1155/2011/475151

38. Kotake Y, Yamada T, Nagata H, Suzuki T, Serita R, Katori N, et al. Improved accuracy of cardiac output estimation by the partial $\mathrm{CO}_{2}$ rebreathing method. J Clin Monit Comput (2009) 23:149-55. doi:10.1007/s10877-009-9172-1

39. Dong L, Wang JA, Jiang CY. Validation of the use of foreign gas rebreathing method for non-invasive determination of cardiac output in heart disease patients. J Zhejiang Univ Sci B (2005) 6:1157-62. doi:10.1631/jzus.2005.B1157

40. Benatar SR, Hewlett AM, Nunn JF. The use of iso-shunt lines for control of oxygen therapy. Br J Anaesth (1973) 45:711-8. doi:10.1093/bja/45.7.711

41. de Abreu MG, Geiger S, Winkler T, Ragaller M, Pfeiffer T, Leutheuser D, et al. Evaluation of a new device for noninvasive measurement of nonshunted pulmonary capillary blood flow in patients with acute lung injury. Intensive Care Med (2002) 28:318-23. doi:10.1007/s00134-001-1204-3

42. Rocco M, Spadetta G, Morelli A, Dell'Utri D, Porzi P, Conti G, et al. A comparative evaluation of thermodilution and partial $\mathrm{CO}_{2}$ rebreathing techniques for cardiac output assessment in critically ill patients during assisted ventilation. Intensive Care Med (2004) 30:82-7. doi:10.1007/s00134-003-2069-4

43. Lang CC, Karlin P, Haythe J, Tsao L, Mancini DM. Ease of noninvasive measurement of cardiac output coupled with peak $\mathrm{VO}_{2}$ determination at rest and during exercise in patients with heart failure. Am J Cardiol (2007) 99:404-5. doi:10.1016/j.amjcard.2006.08.047

44. Palmers PJ, Vidts W, Ameloot K, Cordemans C, Van Regenmortel N, De Laet I, et al. Assessment of three minimally invasive continuous cardiac output measurement methods in critically ill patients and a review of the literature. Anaesthesiol Intensive Ther (2012) 44:188-99.

45. Opotowsky AR, Hess E, Maron BA, Brittain EL, Baron AE, Maddox TM, et al. Thermodilution vs estimated fick cardiac output measurement in clinical practice: an analysis of mortality from the veterans affairs clinical assessment, reporting, and tracking (VA CART) program and Vanderbilt University. JAMA Cardiol (2017)2(10):1090-9. doi:10.1001/jamacardio.2017.2945

46. Rang S, de Pablo Lapiedra B, van Montfrans GA, Bouma BJ, Wesseling KH, Wolf H. Modelflow: a new method for noninvasive assessment of cardiac output in pregnant women. Am J Obstet Gynecol (2007) 196:235.e1-8. doi:10.1016/j.ajog.2006.10.896

47. Hirschl MM, Binder M, Gwechenberger M, Herkner H, Bur A, Kittler H, et al. Noninvasive assessment of cardiac output in critically ill patients by analysis of the finger blood pressure waveform. Crit Care Med (1997) 25:1909-14. doi:10.1097/00003246-199711000-00033

48. Saugel B, Cecconi M, Wagner JY, Reuter DA. Noninvasive continuous cardiac output monitoring in perioperative and intensive care medicine. Br J Anaesth (2015) 114:562-75. doi:10.1093/bja/aeu447

49. Bramwell JC, Hill AV. The velocity of the pulse wave in man. Proc R Soc Lond B (1922) 93(652):298-306. doi:10.1098/rspb.1922.0022

50. Ishihara H, Sugo Y, Tsutsui M, Yamada T, Sato T, Akazawa T, et al. The ability of a new continuous cardiac output monitor to measure trends in cardiac output following implementation of a patient information calibration and an automated exclusion algorithm. J Clin Monit Comput (2012) 26:465-71. doi:10.1007/s10877-012-9384-7

51. Yamada T, Tsutsui M, Sugo Y, Sato T, Akazawa T, Sato N, et al. Multicenter study verifying a method of noninvasive continuous cardiac output measurement using pulse wave transit time: a comparison with intermittent bolus thermodilution cardiac output. Anesth Analg (2012) 115:82-7. doi:10.1213/ ANE.0b013e31824e2b6c

52. Ball TR, Tricinella AP, Kimbrough BA, Luna S, Gloyna DF, Villamaria FJ, et al. Accuracy of noninvasive estimated continuous cardiac output (esCCO) compared to thermodilution cardiac output: a pilot study in cardiac patients. J Cardiothorac Vasc Anesth (2013) 27:1128-32. doi:10.1053/j.jvca. 2013.02.019

53. Biais M, Berthezene R, Petit L, Cottenceau V, Sztark F. Ability of esCCO to track changes in cardiac output. Br J Anaesth (2015) 115:403-10. doi:10.1093/ bja/aev219

54. Thonnerieux M, Alexander B, Binet C, Obadia JF, Bastien O, Desebbe O. The ability of esCCO and ECOM monitors to measure trends in cardiac output during alveolar recruitment maneuver after cardiac surgery: a comparison with the pulmonary thermodilution method. Anesth Analg (2015) 121:383-91. doi:10.1213/ANE.0000000000000753 
55. Wacharasint P, Kunakorn P, Pankongsap P, Preechanukul R. Clinical validation of pulse contour and pulse wave transit time-based continuous cardiac output analyses in Thai patients undergoing cardiac surgery. J Med Assoc Thailand (2014) 97(Suppl 1):S55-60.

56. Biais M, Cottenceau V, Petit L, Masson F, Cochard JF, Sztark F. Impact of norepinephrine on the relationship between pleth variability index and pulse pressure variations in ICU adult patients. Critical Care (2011) 15:R168. doi:10.1186/cc10310

57. Monnet X, Guerin L, Jozwiak M, Bataille A, Julien F, Richard C, et al. Pleth variability index is a weak predictor of fluid responsiveness in patients receiving norepinephrine. Br J Anaesth (2013) 110:207-13. doi:10.1093/bja/aes373

58. Thom O, Taylor DM, Wolfe RE, Cade J, Myles P, Krum H, et al. Comparison of a supra-sternal cardiac output monitor (USCOM) with the pulmonary artery catheter. Br J Anaesth (2009) 103:800-4. doi:10.1093/bja/aep296

59. Boyle M, Steel L, Flynn GM, Murgo M, Nicholson L, O’Brien M, et al. Assessment of the clinical utility of an ultrasonic monitor of cardiac output (the USCOM) and agreement with thermodilution measurement. Crit Care Resusc (2009) 11:198-203.

60. Nguyen HB, Banta DP, Stewart G, Kim T, Bansal R, Anholm J, et al. Cardiac index measurements by transcutaneous Doppler ultrasound and transthoracic echocardiography in adult and pediatric emergency patients. J Clin Monit Comput (2010) 24:237-47. doi:10.1007/s10877-010-9240-6

61. Via G, Hussain A, Wells M, Reardon R, ElBarbary M, Noble VE, et al. International evidence-based recommendations for focused cardiac ultrasound. JAm Soc Echocardiogr (2014) 27: 683.e1-33. doi:10.1016/j. echo.2014.05.001

62. Van den Oever HL, Murphy EJ, Christie-Taylor GA. USCOM (Ultrasonic Cardiac Output Monitors) lacks agreement with thermodilution cardiac output and transoesophageal echocardiography valve measurements. Anaesth Intensive Care (2007) 35:903-10.

63. Huang L, Critchley LA. Study to determine the repeatability of supra-sternal Doppler (ultrasound cardiac output monitor) during general anaesthesia: effects of scan quality, flow volume, and increasing age. Br J Anaesth (2013) 111:907-15. doi:10.1093/bja/aet254

64. Horster S, Stemmler HJ, Strecker N, Brettner F, Hausmann A, Cnossen J, et al. Cardiac output measurements in septic patients: comparing the accuracy of USCOM to PiCCO. Crit Care Res Pract (2012) 2012:270631. doi:10.1155/2012/270631

65. Sackner MA, Hoffman RA, Stroh D, Krieger BP. Thoracocardiography. Part 1: noninvasive measurement of changes in stroke volume comparisons to thermodilution. Chest (1991) 99:613-22. doi:10.1378/chest.99.3.613

66. Kaplan V, Bucklar GB, Bloch KE. Noninvasive monitoring of cardiac output during exercise by inductance cardiography. Med Sci Sports Exerc (2003) 35:747-52. doi:10.1249/01.MSS.0000064997.58069.A6

67. Bloch KE, Jugoon S, de Socarraz H, Manning K, Sackner MA. Thoracocardiography: noninvasive monitoring of left ventricular stroke volume. J Crit Care (1998) 13:146-57. doi:10.1016/S0883-9441(98)90019-3

68. Bloch KE, Baumann PC, Stocker R, Russi EW. Noninvasive monitoring of cardiac output in critically ill patients with thoracocardiography. Am J Respir Crit Care Med (1997) 155:26-31. doi:10.1164/ajrccm.155.1.9001284

69. Peyton PJ, Chong SW. Minimally invasive measurement of cardiac output during surgery and critical care: a meta-analysis of accuracy and precision. Anesthesiology (2010) 113:1220-35. doi:10.1097/ALN.0b013e3181ee3130

70. Joosten A, Desebbe O, Suehiro K, Murphy LS, Essiet M, Alexander B, et al. Accuracy and precision of non-invasive cardiac output monitoring devices in perioperative medicine: a systematic review and meta-analysisdagger. $\mathrm{Br}$ J Anaesth (2017) 118:298-310. doi:10.1093/bja/aew461

71. Chong SW, Peyton PJ. A meta-analysis of the accuracy and precision of the ultrasonic cardiac output monitor (USCOM). Anaesthesia (2012) 67:1266-71. doi:10.1111/j.1365-2044.2012.07311.x

Conflict of Interest Statement: LN has no conflict of interest regarding this publication. PS perceived consulting fees from Edwards and Cheetah Medical prior to 2000 .

Copyright (c) 2017 Nguyen and Squara. This is an open-access article distributed under the terms of the Creative Commons Attribution License (CC BY). The use, distribution or reproduction in other forums is permitted, provided the original author(s) or licensor are credited and that the original publication in this journal is cited, in accordance with accepted academic practice. No use, distribution or reproduction is permitted which does not comply with these terms. 